\title{
Herpes simplex lymphadenitis: a case report and review of the published work
}

\author{
M LAPSLEY, ${ }^{*}$ P KETTLE, $\dagger \mathrm{J}$ M SLOAN* \\ From the Departments of *Pathology and $†$ Haematology, Royal Victoria Hospital, Belfast BT12 $6 B A$
}

SUMMARY Viral lymphadenitis may lead to a histological appearance that can simulate malignancy. The histological features of herpes simplex lymphadenitis have not previously been described in detail. We report a case of proved herpes simplex lymphadenitis in a 30 year old man which was characterised by a pronounced proliferation of immunoblasts. The microscopical findings are described and the published work is reviewed.

Infectious mononucleosis had long been recognised as a major source of difficulty in diagnosis in lymph node histopathology,' but other viral infections may give rise to similar problems. Problems in interpretation arise because of distortion and apparent effacement of lymph node architecture and because of the large numbers of large dividing cells seen under high power examination. These problems are often further compounded by lack of experience in interpreting biopsy material from patients suffering from viral illness, since lymph node excision is not usually deemed necessary from a clinical point of view.

We report a case of lymphadenitis in a 30 year old man with serologically proved herpes simplex infection, which was characterised by pronounced immunoblastic proliferation.

\section{Case report}

\section{CLINICAL FEATURES}

A 30 year old man presented with a short history of increasing tiredness and general malaise, with a widespread rash. He had no night sweats and no pruritus, and he was not taking any drugs. There was no history of immunisation. His children were convalescing from a rash which had been diagnosed clinically as varicella.

By the time of examination the rash had faded considerably. There were a few raised papules on the trunk and limbs with occasional raised erythematous areas. There was generalised lymphadenopathy, but all the nodes were less than 0.5 $\mathrm{cm}$ in diameter. There was no hepatosplenomegaly, and he was not feverish. No cold sores or herpetic whitlow were identified.

His haemoglobin concentration was $15.6 \mathrm{~g} / \mathrm{dl}$ and his white cell count $8.2 \times 10^{9} / 1$, with a normal differential count. The erythrocyte sedimentation rate was $2 \mathrm{~mm}$ in the first hour. Biochemical screening showed no abnormality, and serum immunoglobulin values were normal. Bone marrow trephine biopsy was normal. There was no hilar lymphadenopathy on chest radiography, and computed tomography of the abdomen showed a few small pelvic lymph nodes, which were not thought to be important.

Serological screening showed no change in titre to varicella zoster or cytomegalovirus. There was, however, a rise in titre to herpes simplex to $1 / 640$, which fell to $1 / 160$ two months later. Further typing was not performed. The result of a Paul Bunnell test was negative.

About eight months after referral the patient is well and asymptomatic. The lymph nodes have regressed without treatment.

A lymph node biopsy was performed shortly after the onset of symptoms, and the findings are presented.

\section{PATHOLOGICAL FINDINGS}

The lymph node was fixed in formalin, processed, and embedded in wax. Sections were cut and stained with haematoxylin and eosin. Giemsa, periodic acid Schiff, and reticulin (Foot) stains were also performed. Further paraffin sections were stained for cytoplasmic immunoglobulin light and heavy chains by an immunoperoxidase method.

The lymph node structure was distorted, but the sinus architecture was preserved. There was pronounced expansion of the paracortical regions, and several atrophic germinal centres remained around 


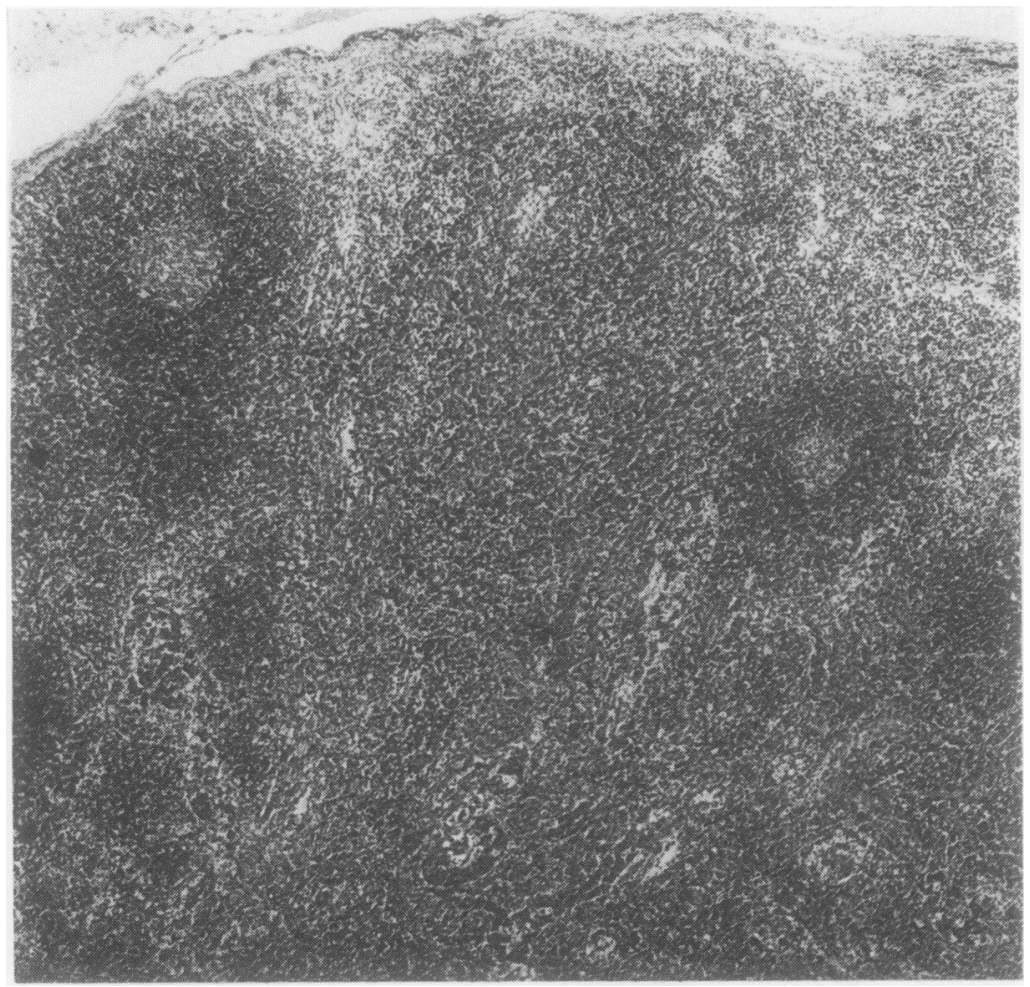

Fig. 1 Lymph node showing expansion of the parafollicular areas, preservation of small atrophic germinal centres, and remaining medullary sinuses. Original magnification $\times 40$.

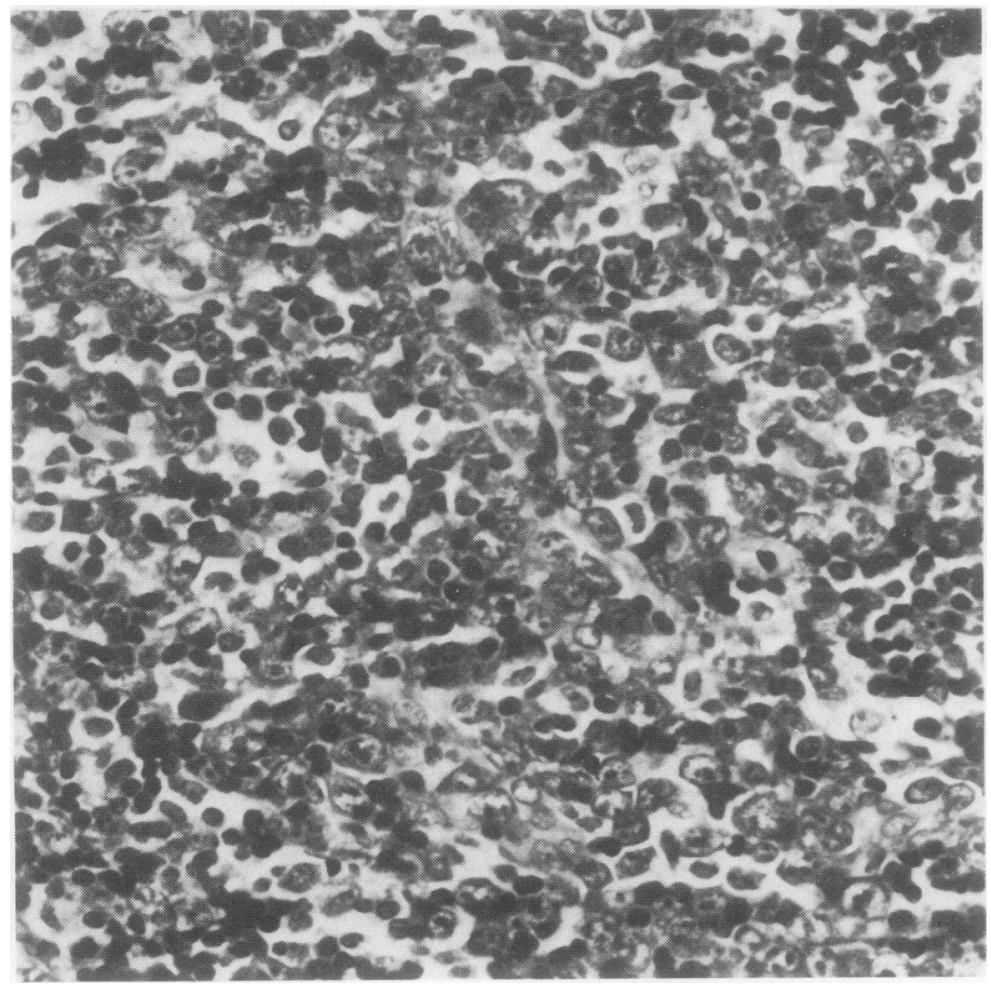

Fig. 2 Infiltrate in interfollicular areas. There is an intimate mixture of immunoblasts, centroblasts, small lymphocytes, and occasional histiocytes. A small venule is present and has prominent endothelial cells. Original magnification $\times 400$. 
the periphery of the node (Fig. 1). The interfollicular infiltrate was composed of a mixture of cells. There were abundant immunoblasts, which are large cells with pyroninophilic cytoplasm and a vesicular nucleus containing a single large eosinophilic nucleolus. Many of these were in mitosis. Intimately interspersed between these were many lymphocytes, with occasional plasmacytoid cells and macrophages (Fig. 2). There was no sheeting of immunoblasts. The endothelial cells of the epithelioid venules were prominent, but the small blood vessels did not show an arborising pattern. There was no necrosis, and no extension of lymphoid cells through the capsule of the node. There was no invasion of blood vessel walls. Immunoperoxidase studies showed only minimal production of both light chains. No heavy chains were produced. An immunoperoxidase stain for herpes simplex type II was negative. Unfortunately, fresh unfixed material was not available for lymphoid cell surface marker studies.

\section{Discussion}

Lymph node biopsy is not normally required in the diagnosis of viral illness, and the importance of the histological appearances lies in the recognition of the somewhat alarming pattern as being due to a benign self limiting condition. Many other benign conditions can simulate malignancy in lymph nodes, ${ }^{2}$ including herpes zoster $^{3}$ and infectious mononucleosis. ${ }^{1}$ Postvaccinial lymphadenitis may give a similar picture to viral lymphadenitis, ${ }^{3}$ although there was no history of immunisation in this case. To our knowledge the histological findings in herpes simplex lymphadenitis have not previously been described in detail, although Tindle briefly described herpetic lymphadenitis in general as being characterised by immunoblastic proliferation. ${ }^{4}$

The histological appearances seen in this patient's lymph node are similar to those reported after infection by other members of the herpes group, such as infectious mononucleosis ${ }^{1}$ and herpes zoster infection. ${ }^{3}$ In all these cases hypercellularity and expansion of paracortical areas are the main features. Similar features have been shown in rabbits infected with herpes virus of bovine malignant catarrhal fever'; the proliferating cells have been shown to be $T$ lymphoblasts in this disease. ${ }^{6}$

We believe that the changes in this lymph node were due to a proliferation of $\mathrm{T}$ immunoblasts as a reaction to herpes simplex virus antigen. This interpretation is supported by the parafollicular location of the dividing cells, in between the atrophic germinal centres. This is the $T$ zone of the lymph node. ${ }^{7}$ In addition, staining for immunoglobulin by the immunoperoxidase method showed little evidence of immunoglobulin production, which, if present, would suggest $B$ cell function. The $T$ immunoblast is believed to be the precursor of the cytotoxic T cell. ${ }^{7}$ Animal studies have suggested that a $T$ cell reaction would be consistent with the immune response to herpes simplex infection under experimental conditions. Stimulated mouse $T$ cells can be specifically sensitised to herpes simplex antigen. ${ }^{89}$ These cells are of the cytotoxic subgroup. Another study has shown that herpes simplex virus can replicate within activated human T cells. ${ }^{10}$ Thus, at least in the mouse, the normal response to herpes simplex infection would seem to include $T$ cell transformation and proliferation.

Herpes simplex infection in man is well known for causing cold sores, genital lesions, and encephalitis. Reports of lymphatic complications are rarer, but lymphangitis, usually associated with lymphadenopathy, has been described after herpes simplex infection of the hand. ${ }^{112}$ Systemic infection may rarely occur in pregnancy after genital herpes, and lymphadenopathy is considered to be an important sign of generalised infection. ${ }^{13}$ Unfortunately, no biopsy material was available to the authors of the latter report. It has also been suggested ${ }^{14}$ that generalised herpes simplex infection is uncommon and usually fatal and occurs in immunodeficient patients. Our experience with this case suggests that this is not always so.

It is uncertain what the origin of the infection in the present case was, or indeed why a healthy $\mathbf{3 0}$ year old man should develop a systemic herpes simplex infection in the absence of any localised lesion. His children had been suffering from a febrile illness with an associated rash, which was diagnosed clinically as varicella. This diagnosis was not proved, however, and the illness may have been the same as that in our patient.

The clinical findings were those of a benign self limiting condition, and the appearances in the lymph node would support this. In particular, the preservation of germinal centres and medullary sinuses and the absence of any sheeting or clumping of immunoblasts suggest a benign condition. Finally, should a case such as this be misdiagnosed as malignant, a short course of chemotherapy or radiotherapy would be considered "curative," and the true diagnosis might never be made. The hazards of cytotoxic therapy and the anxiety generated in both the patient and his family after a diagnosis of malignancy, possibly for many years subsequently, make the recognition of this and similar conditions of great importance.

We thank Professor JM Bridges for his permission to report this case. 


\section{References}

' Salvador AH, Harrison EG, Kyle RA. Lymphadenopathy due to infectious mononucleosis: Its confusion with malignant lymphoma. Cancer 1971;27:1029-40.

${ }^{2}$ Dorfman RF, Warnke R. Lymphadenopathy simulating the malignant lymphomas. Hum Pathol 1974;5:519-50.

${ }^{3}$ Hartsock RJ. Postvaccinial lymphadenitis. Hyperplasia of lymphoid tissue that simulates malignant lymphomas. Cancer 1968;21:632-49.

4 Tindle BH. The haemopoietic system. In: Coulson WF, ed. Surgical Pathology. Philadelphia: JB Lippencott Company. 1978;903-4.

${ }^{5}$ Edington N, Patel J, Russell PH, Plowright W. The nature of the acute lymphoid proliferation in rabbits infected with the herpes virus of bovine malignant catarral fever. Eur J Cancer 1979; 15: 1515-22.

- Rossiter PB. Proliferation of T lymphoblasts in rabbits fatally infected with the herpes virus of malignant catarral fever. Clin Exp Immunol 1983;54:547-53.

' Lennert K. Malignant lymphomas other than Hodgkin's disease Berlin: Springer Verlag, 1978;24-51.

${ }^{8}$ Jennings SR, Rice PL, Pan S, Knowles BB, Trevethia SS. Recog- nition of herpes $\mathrm{H}-2 \mathrm{~b}$ simplex virus antigens on the surface of mouse cells of the haplotype by virus-specific cytotoxic $\mathrm{T}$ lymphocytes. J Immunol 1984; 132:475-81.

${ }^{9}$ Rouse BT, Wagner H. Frequency of herpes simplex virus-specific cytotoxic $\mathrm{T}$ lymphocyte precursors in lymph node cells of infected mice. Immunology 1984;51:57-64.

${ }^{10}$ Braun RW, Teute HK, Kirchner H, Munk K. Replication of herpes simplex virus in human $\mathrm{T}$ lymphocytes: characterization of the viral target cell. $J$ Immunol 1984;132:914-9.

" Howard WR, Taylor JS, Steck WD. Lymphatic complications of manual herpes simplex infection. Cutis 1979;23:580-3.

${ }^{12}$ Dorman JM. Herpetic lymphangitis in a student population. $J$ Adolesc Health Care 1982;3:49-50.

${ }^{13}$ Hillard P, Seeds J, Cefalo. R. Disseminated herpes simplex in pregnancy: Two cases and a review. Obstet Gynecol Surv 1982;37:449-53.

14 Schaffer R, Ormanns W, Pfeifer U. Post mortem diagnosis of herpes simplex infections. Verh Dtsch Ges Pathol 1981;65:230-4.

Requests for reprints to: Dr M Lapsley, Department of Histopathology, Guy's Hospital Medical School, London Bridge, London SE1 9RT, England. 